\title{
Two methods for firn-area and mass-balance monitoring of Svalbard glaciers with SAR satellite images
}

\author{
Max KÖNIG, ${ }^{1}$ Jan-Gunnar WINTHER, ${ }^{1}$ JaGk KOHLER, ${ }^{1}$ FlORIAn KÖNIG ${ }^{2}$ \\ ${ }^{1}$ Norwegian Polar Institute, Polar Environmental Centre, $\mathcal{N}-9296$ Tromsø, Norway \\ E-mail:max@npolar.no \\ ${ }^{2}$ Institut für Physische Geographie, Albert-Ludwigs-Universität, D-79085 Freiburg, Germany
}

\begin{abstract}
This paper presents two methods for glacier monitoring on Svalbard using synthetic aperture radar (SAR) satellite images. Both methods were developed on glaciers in the Kongsfjorden area. The first method monitors the firn area extent and the firn line over time by thresholding and filtering the SAR image. Manual detection of the threshold is preferable, but using a constant threshold for all images also gives adequate results. A retreat of the firn-line position is visible, especially on Kongsvegen, corresponding to consecutive years of negative mass balance. The second method applies a $k$-means classification to three clusters on the glacier surface. The areal extent of the resulting class on the upper part of the glacier correlates remarkably well with the independently measured mass balance of Kongsvegen, having a correlation coefficient of around 0.89 for the various glaciers. This is because the snow from the accumulation area influences the $k$ means classification. Thus, on glaciers where mass-balance values are available, new mass-balance values can be predicted solely from SAR images. For glaciers where no mass balance is available, the area change cannot be calibrated to absolute mass-balance values, but relative changes can be predicted.
\end{abstract}

\section{INTRODUGTION}

One of the principal aims in using satellites for glacier monitoring is to identify distinct zones on the glacier surface and to observe their extent and variation over several years (see, e.g., Fahnestock and others, 1993; Smith and others, 1997; Partington, 1998). An overview of earlier studies and a detailed summary of how to identify these zones can be found in König and others (2001b). Recent studies have shown that synthetic aperture radar (SAR) is able to detect areas of glacier ice, superimposed ice and firn on Svalbard glaciers (Engeset and others, 2002; König and others, 2002). Different surface characteristics on the glacier make this detection possible. The homogeneous glacier ice does not reflect much of the incoming SAR signal back to the sensor, resulting in low backscatter values. The high air-bubble content in superimposed ice is the likely cause of medium backscatter values, whereas the snow crystals in firn are good reflectors leading to high backscatter in the firn area (König and others, 2002; see also Fig. 1).

This paper presents two methods for glacier monitoring on Svalbard using SAR. The first method is based on monitoring the firn area extent and thus the firn-line position over time as suggested by Engeset and others (2002) and König and others (2002). In contrast to the equilibrium line, the firn-line position will smooth out yearly variations and show long-term trends (König and others, 2002), as shown below in more detail. The second method is based on a $k$ means classification of the glacier surface. The areal extent of one of the classified areas shows a remarkable correlation with glacier mass balance, which can be used for massbalance prediction.

\section{STUDY AREA}

The glaciers in this study are located in the northwest of Spitsbergen, Svalbard, close to the research facility $\mathrm{Ny}$ Ålesund (Fig. 2). Kongsvegen $\left(78^{\circ} 48^{\prime} \mathrm{N}, 13^{\circ} \mathrm{E}\right)$, the main focus of our research, is a surge-type glacier about $25 \mathrm{~km}$ long, $102 \mathrm{~km}^{2}$ in area and with a very gentle surface slope of $0.5-2^{\circ}$. The glacier flows from an ice divide at an altitude of $800 \mathrm{~m}$ down to sea level, where it shares its calving front with the fast-flowing Kronebreen. Kongsvegen has a flow velocity of $<4 \mathrm{~m} \mathrm{a}^{-1}$ (Melvold and Hagen, 1998). This is insufficient to transport all accumulated mass to the ablation area and indicates that the glacier may be building up to a new surge (Lefauconnier and others, 1999), the last surge having occurred in 1948 (Liestøl, 1988; Melvold and Hagen, 1998). Mass balance on Kongsvegen has been measured annually by the Norwegian Polar Institute since 1987 using nine stakes positioned along the glacier's centre line (Hagen and others, 1999).

Besides Kongsvegen, we have studied Uvêrsbreen $\left(78^{\circ} 47^{\prime} \mathrm{N}, 12^{\circ} 32^{\prime} \mathrm{E}\right)$, Comfortlessbreen $\left(78^{\circ} 46^{\prime} \mathrm{N}, 12^{\circ} 08^{\prime} \mathrm{E}\right)$ and Aavatsmarkbreen $\left(78^{\circ} 42^{\prime} \mathrm{N}, 12^{\circ} 13^{\prime} \mathrm{E}\right)$. These glaciers are comparable in size to Kongsvegen, flow in the same direction and thus are oriented similarly to the SAR sensor, all four being parallel to its look direction. In contrast to Kongsvegen, little research has been done on these three glaciers. We have also tested the methods developed in this paper on the smaller glaciers on the Brøggerhalvøya peninsula, such as midre Lovénbreen $\left(6 \mathrm{~km}^{2} ; 78^{\circ} 53^{\prime} \mathrm{N}, 12^{\circ} 04^{\prime} \mathrm{E}\right)$, Austre Brøggerbreen ( $\left.12 \mathrm{~km}^{2} ; 78^{\circ} 53.5^{\prime} \mathrm{N}, 11^{\circ} 50^{\prime} \mathrm{E}\right)$ and Austre Lovénbreen $\left(6.2 \mathrm{~km}^{2} ; 78^{\circ} 52.7^{\prime} \mathrm{N}, 12^{\circ} 09^{\prime} \mathrm{E}\right)$. Mass balance on Austre Brøggerbreen has been measured annually by the 


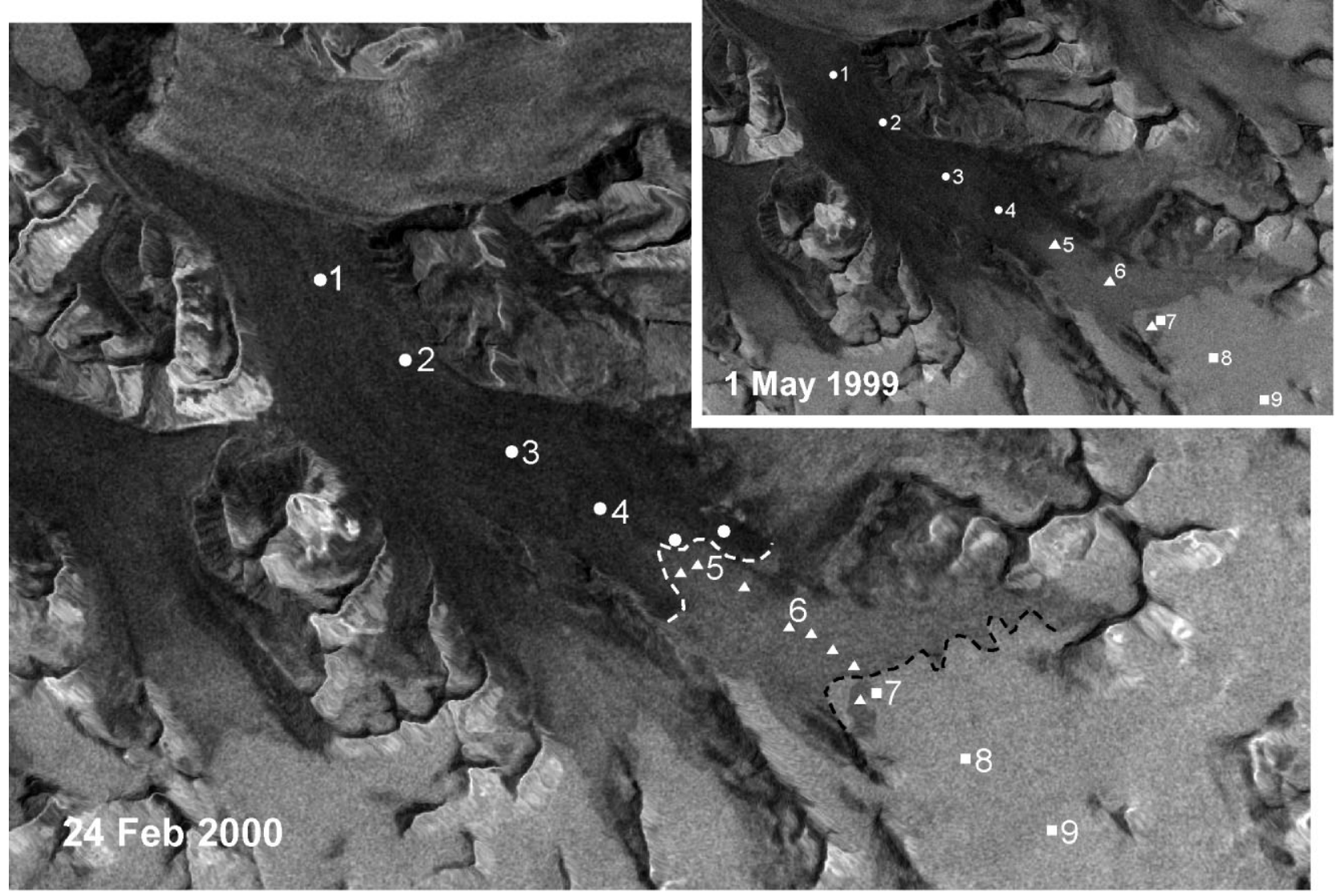

Fig. 1. ERS-2 SAR images from Kongsvegen, 1 May 1999 and 24 February 2000. Sites where ice-core analysis indicated presence of glacier ice (circles) coincide with an area of comparably low backscatter; superimposed-ice-core sites (triangles) coincide with an area of medium backscatter; and firn-core sites (squares) coincide with an area of high backscatter. The dotted lines indicate the boundaries of these zones. Note the highly crevassed tongue of the fast-flowing Kronebreen (upper left corner) giving high backscatter. See Figure 2 for geographic information, and König and others (2002) for more detail. The SAR image data were provided by the European Space Agency ( (C) ESA 2000).

Norwegian Polar Institute since 1966, and on midre Lovénbreen since 1967.

Further information on Kongsvegen and other glaciers in the Kongsfjorden area can be found in Liestøl (1988), Hagen and Liestøl (1990), Hagen and others (1993), Winther (1993) and Lefauconnier and others (1999).

\section{SATELLITE DATA}

We used a time series of yearly winter SAR images for the period 1992-2003 from the study area (see Table 1). The dry winter snow cover is invisible to $\mathrm{SAR}$ at $5.3 \mathrm{GHz}$, and wintertime SAR images thus show the previous end-of-summer situation during the whole winter on Svalbard. This can be seen in König and others (2002), where images from October, March and May only show minor differences. The same images were from neighbouring tracks, showing additionally that a slight difference in image geometry has no noticeable effect. The years mentioned in this paper refer to the spring of the year in which the SAR images were taken. These images then show the mass-balance situation of the previous year (e.g. an image from spring 1992 corresponds to the mass-balance year 1990/91).

The ERS images were calibrated to absolute backscatter (dB) using the European Space Agency's European
Remote-sensing Satellite (ERS) SAR Toolbox (now called Basic EnviSat SAR Toolbox, available at http://envisat .esa.int/services/best/). The calibration algorithm used in the SAR Toolbox is described in detail in Laur and others (1998). A $5 \times 5$ moving average filter was applied to all SAR images to remove speckle.

On SAR images, points with higher elevation are displaced towards the SAR sensor, causing layover and foreshortening. Geocoding and removal of displacement by

Table 1. All SAR images available for this study (C-band, 5.3 GHz type PRI (pulse-repetition interval), frame 1989)

\begin{tabular}{lccc}
\hline Sensor & Date & Orbit & Track \\
\hline ERS-1 SAR & 30 Apr 1992 & 4133 & 481 \\
ERS-1 SAR & 4 Feb 1993 & 8141 & 481 \\
ERS-1 SAR & 16 Dec 1993 & 12650 & 481 \\
ERS-1 SAR & 8 Apr 1995 & 19507 & 481 \\
ERS-1 SAR & 17 Feb 1996 & 24016 & 481 \\
ERS-2 SAR & 9 Mar 1997 & 9854 & 481 \\
ERS-2 SAR & 29 Mar 1998 & 15365 & 481 \\
ERS-2 SAR & 1 May 1999 & 21062 & 166 \\
ERS-2 SAR & 24 Feb 2000 & 25342 & 438 \\
ERS-2 SAR & 7 Jan 2001 & 29894 & 481 \\
ERS-2 SAR & 3 Mar 2002 & 35906 & 481 \\
ERS-2 SAR & 23 Mar 2003 & 41417 & 481 \\
& & & \\
\hline
\end{tabular}




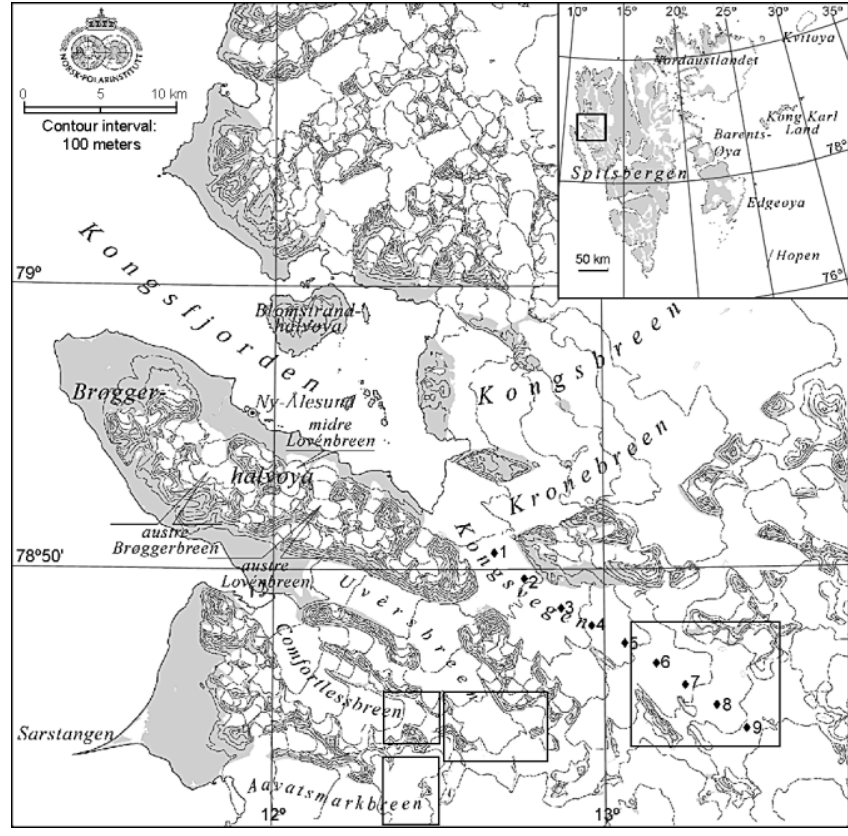

Fig. 2. The location of all glaciers in this study. The rectangles mark the positions of Kongsvegen in Figure 5 and of the four glaciers shown in Figure 7. Compare stake positions on Kongsvegen for position of Figures 1 and 8.

layover and foreshortening was done using an algorithm by Guindon and Adair (1992) as implemented in the software package PCIWorks, and is based on referencing the SAR images to a simulated SAR image created from a digital elevation model (DEM). The DEM, covering all of Svalbard, has been produced by the Mapping Section of the Norwegian Polar Institute from topographical maps $(1: 100000)$ and has a pixel size of $20 \mathrm{~m}$ with an estimated vertical accuracy of $20-50 \mathrm{~m}$. We tested the accuracy of the geocoding process using known ground-control points located on mountaintops. Deviations are 30-300 m, with an average deviation of $96 \mathrm{~m}$ in the east-west direction and of $220 \mathrm{~m}$ in the north-south direction. These, however, are values for locations at high elevations and at steep slopes, where displacement is very strong to begin with. In addition, these are deviations from the absolute pixel positions. Relative errors between the various images are expected to be much smaller, since the same simulated SAR image and ground-control points were used and the images are thus coreferenced. Kongsvegen is nearly flat, so we expect an accuracy of better than $100 \mathrm{~m}$. Also, no major changes in surface elevation are expected in the 12 year time series. The pixel size of the geocoded image is $20 \mathrm{~m}$.

\section{FIRN LINE AND SNOWLINE}

The terms snowline and firn line vary in their meaning in the literature. The following describes the usage of these terms in the present paper, which is important for understanding the methods presented.

Figure 3 shows a schematic cross-cut of a glacier at the end of summer. During the previous winter, mass had accumulated on all parts of the glacier, mainly in the form of snow and superimposed ice. At the end of the summer, as shown in Figure 3, all snow and superimposed ice from the previous winter will have melted away on the lower parts of the glacier. This is the ablation area, where the glacier loses

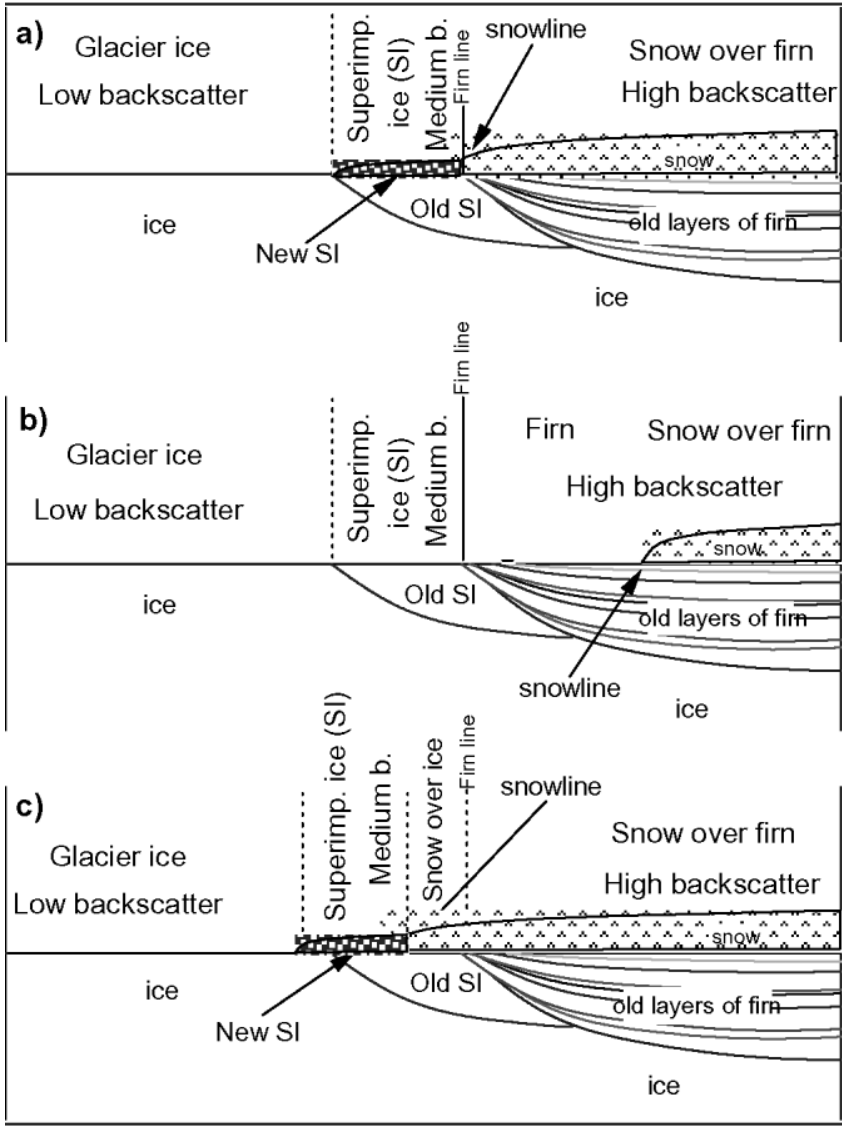

Fig. 3. Stratigraphy of a glacier, with the late-summer snow cover of the present year on top. Three possible cases are drawn: the snowline ( $a$ ) at the same altitude as the firn line, and $(b)$ above and (c) below the firn line. Note the resulting SAR backscatter and that firn and snow can be indistinguishable due to similar backscatter (König and others, 2001a).

more mass than it gains. On the higher parts of the glacier, there will still be snow, and possibly some superimposed ice, left from the previous winter. This is the accumulation area, where the glacier gains more mass than it loses. The dividing line between the accumulation and ablation areas is the equilibrium line, where the glacier gains as much mass as it loses. In Figure 3b, the equilibrium line will principally be the lower boundary of the snow remaining from the previous winter, which we call the snowline. When newly formed superimposed ice is present, as in Figure $3 \mathrm{a}$ and c, the equilibrium line will be the lower boundary of the superimposed-ice zone (Paterson, 1994). In any case, the end-of-summer snowline will have large annual variations. In years with negative mass balance it will be further upglacier (Fig. 3b), while in years with positive mass balance it will be further down-glacier (Fig. 3c).

The firn area and the firn line are different from the snowline described above. The firn area is a combination of many years' layers of old snow (i.e. firn), as seen in Figure 3. The lower boundary of the firn area, where the firn-ice transition is seen on the glacier surface, is the firn line. The firn line will not have strong annual variations (König and others, 2002). Several consecutive years of negative mass balance, however, will cause increased melting at the firn line and thus a retreat of the firn line. Several consecutive years of positive mass balance will cause the firn line to advance further down-glacier. The firn-line variations thus smooth out annual variations and display long-term trends. 

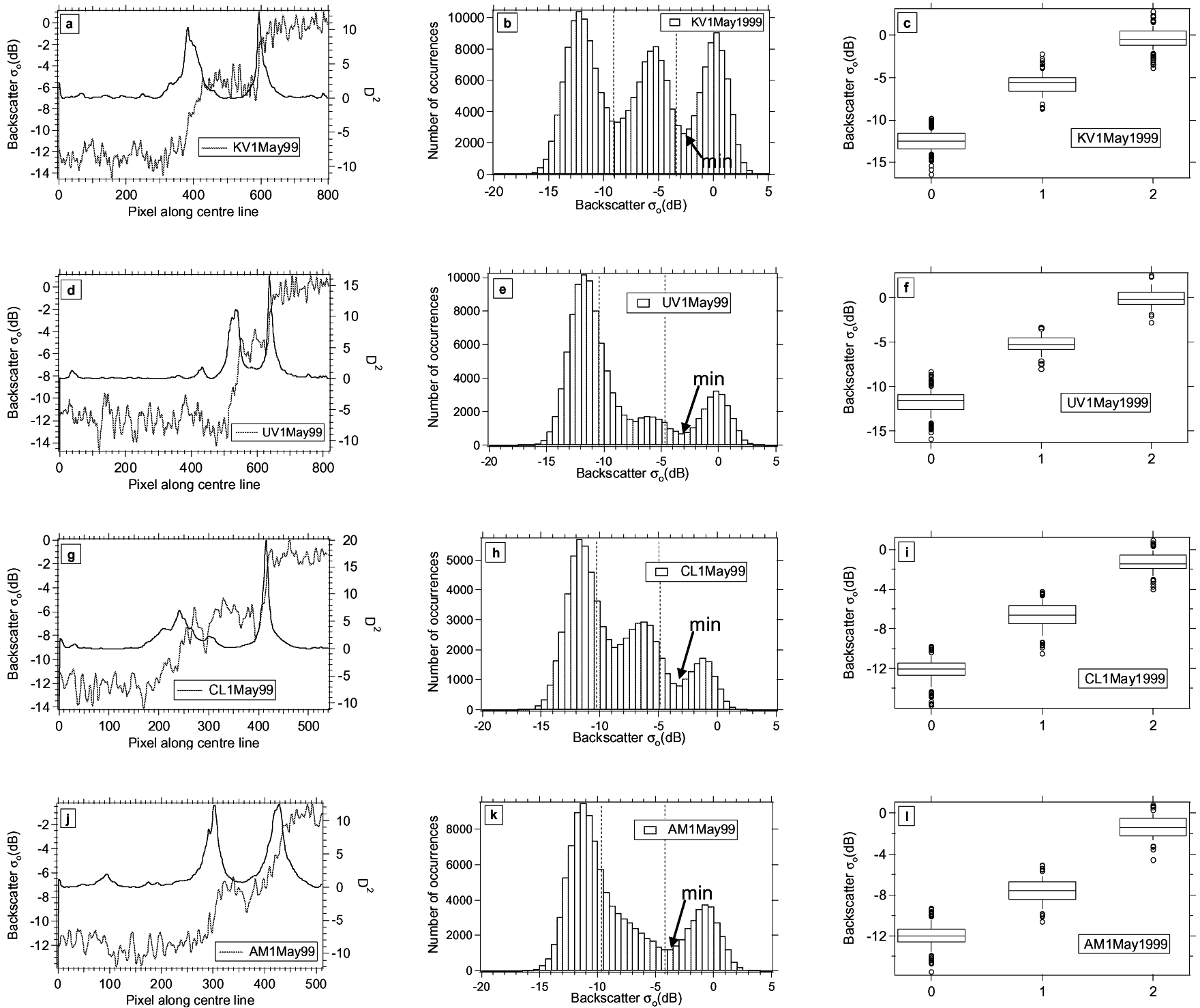

Fig. 4. Centre-line profiles $(a, d, g, j)$, histograms $(b, e, h, k)$ and box plots $(c, f, i, l)$ for Kongsvegen $(a-c)$, Uvêrsbreen $(d-f)$, Comfortlessbreen $(g-i)$ and Aavatsmarkbreen $(j-l)$. The results of the segmentation filter can be seen in the profile plot, showing peaks at the boundaries between glacier ice and superimposed ice and between superimposed ice and firn. $D^{2}$ represents the difference between the mean to the right and the left of any point, using a formula from Davis (1986). In the histogram, "min" indicates the minimum chosen for thresholding ( Table 2). The dotted lines indicate the thresholds chosen by the k-means algorithm (see text for further details).

The dry winter snow cover remains invisible to the SAR, and all winter SAR images show the previous end-of-summer situation (Fig. 3). König and others (2002) concluded that the snowline is not visible on SAR images on Svalbard glaciers, since snow and firn will have comparable backscatter, and only the lower-lying firn line will be visible (Fig. 3b). We therefore attempt to derive an algorithm for firn area monitoring.

\section{STATISTICAL ANALYSIS OF THE THREE SURFAGE TYPES}

Our first method attempts to monitor the extent of the firn area. This requires that the three surface types (glacier ice, superimposed ice and firn) have a distinct backscatter so that they can be separated reliably each year. To examine this in more detail, we extracted longitudinal profiles along the glaciers (Fig. 4a, d, g and j). Profiles were chosen, rather than several small test areas, since profiles allow the detec- tion of changes along the glacier, such as transition zones between surface types. While choosing the profiles, it became clear that for some profiles the superimposed-ice zone is, to some extent, characterized by a linearly increasing backscatter between the glacier ice and the firn. This is most likely due to an increasing thickness of superimposed ice along the profile. In other cases, the transition between glacier ice and superimposed ice is almost stepwise. Transition zones were avoided as far as possible for the profiles in this analysis, and profiles with a stepwise transition were selected (Fig. 4a, d, g and j). Only these will show the characteristic backscatter of a pure superimposed-ice zone, while the backscatter in the transition zone is most likely caused by a combination of a thin superimposed-ice layer and the underlying glacier ice. The zones were then divided into segments, each containing only one surface type. For Kongsvegen, the profile followed the centre-line stakes marked in Figure 3, and the segments extend from stake 1 to stake 4, stake 5 to the firn line, and stake 7 to stake 9 .

A histogram of SAR backscatter of the glacier surface 

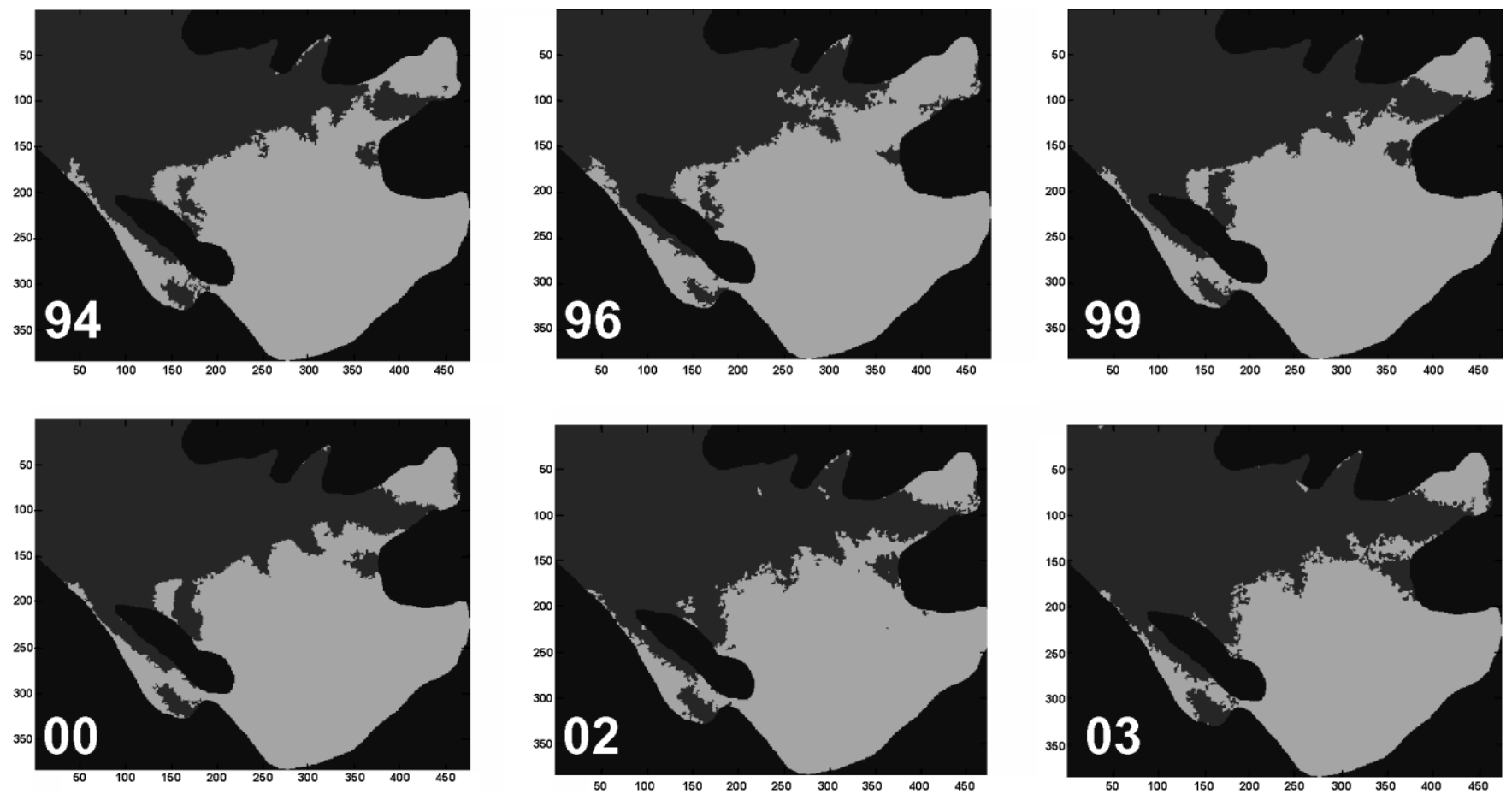

Fig. 5. A close-up of the firn area of Kongsvegen in 1994, 1996, 1999, 2000, 2002 and 2003, after applying the manual thresholds in Table 2 and a regional extrema filter as explained in the text. A retreat of the firn line is visible, especially in recent years. These results are also plotted against time in Figure 6a. The location is marked as a rectangle in Figure 2. Compare also with the actual SAR image in Figure 1.

typically shows three peaks for the glaciers in this study (Fig. 4b, e and h). These correspond to glacier ice, having the lowest backscatter, superimposed ice, having medium backscatter, and firn, having the highest backscatter, which is also seen in the SAR image (Fig. 1; König and others, 2002). In some years these three peaks are clearly separated (e.g. Fig. 4b and h), and in other years one of the peaks may be much less distinct (Fig. 4e) or not visible (Fig. 4k). The box plots show that the three surface types, as determined from the profile segments, have distinct backscatter and thus can be distinguished from each other in any year (Fig. 4c, f, i and 1 ). This is also seen in the centre-line profiles, where the three surface types appear as distinct steps from one backscatter level to the next in most years (Fig. 4a and $\mathrm{c}$ and $\mathrm{g}$ and $\mathrm{j}$ ).

We applied a segmentation filter (Davis, 1986) to the profile to see if surface type boundaries, especially the firn line, are detectable in every year. The results of a segmentation filter can be seen in the profile plot (Fig. $4 a, d, g$ and j). The filter calculates the difference between the average of an 80-point window to the left and an 80-point window to the right of any data point. In a homogeneous area, this difference will be close to zero. At a boundary, however, the difference will differ from zero and the boundary will appear as a peak. Before applying the segmentation filter, the profile was smoothed using Gaussian 8-pass binominal smoothing to reduce noise. We applied this segmentation filter to profiles from all years for all four glaciers. The firn line, i.e. the boundary between superimposed ice and firn, is detected in all cases, mostly as a very distinct peak as in Figure $4 \mathrm{a}, \mathrm{d}, \mathrm{g}$ and $\mathrm{j}$ (the peak to the right). The boundary between superimposed ice and glacier ice is also detected, but the peak is broader and not as distinct in some cases (e.g. Fig. 4g). We can conclude, however, that the firn line is a clearly detectable feature in all years.

\section{FIRN-AREA MONITORING}

As discussed above, the histogram of SAR backscatter of the glacier surface for the four glaciers in this study typically shows three peaks corresponding to the three glacier surface types. The firn area can be displayed by thresholding the SAR image at the minimum in the histogram separating superimposed ice and firn. In Figure 4, this minimum is indicated by the arrow labelled "min". On Kongsvegen, for example, this minimum is clearly visible at $-2.6 \mathrm{~dB}$ (Fig. $4 \mathrm{~b}$ ), while on Aavatsmarkbreen it is detectable at $-4.0 \mathrm{~dB}$ (Fig. 4k). The thresholds thus determined for the various glaciers in the available years vary between -1.7 and $-4.0 \mathrm{~dB}$ (Table 2).

Figure 5 displays the results after applying these thresholds to the images. A filter was applied after thresholding in

Table 2. Manual firn area threshold (thresh; $d B$ ) for all glaciers and Kongsvegen mass balance (KV, Kongsvegen; $U V$, Uvêrsbreen; CL, Comfortlessbreen; AM, Aavatsmarkbreen)

\begin{tabular}{|c|c|c|c|c|c|}
\hline Year & $K V$ thresh & $U V$ thresh & CL thresh & $A M$ thresh & $\begin{array}{l}K V \text { net } \\
\text { balance }\end{array}$ \\
\hline 1992 & -2.4 & -3.5 & -3.3 & -3.7 & 0.43 \\
\hline 1993 & -3.0 & -3.4 & -2.7 & -3.5 & 0.34 \\
\hline 1994 & -3.3 & -3.5 & -4.0 & -3.5 & -0.32 \\
\hline 1995 & -2.3 & -3.0 & -3.0 & -2.7 & 0.50 \\
\hline 1996 & -2.7 & -3.3 & -3.2 & -3.0 & -0.18 \\
\hline 1997 & -2.0 & -2.5 & -2.5 & -2.8 & 0.38 \\
\hline 1998 & -2.6 & -2.5 & -2.5 & -2.2 & 0.10 \\
\hline 1999 & -2.6 & -3.0 & -3.4 & -4.0 & -0.70 \\
\hline 2000 & -2.8 & -3.1 & -3.5 & -3.5 & -0.15 \\
\hline 2001 & -2.7 & -3.1 & -3.5 & -4.0 & 0.39 \\
\hline 2002 & -1.7 & -2.5 & -3.2 & -2.8 & -0.54 \\
\hline 2003 & -2.8 & -3.0 & -3.5 & -3.2 & -0.21 \\
\hline
\end{tabular}



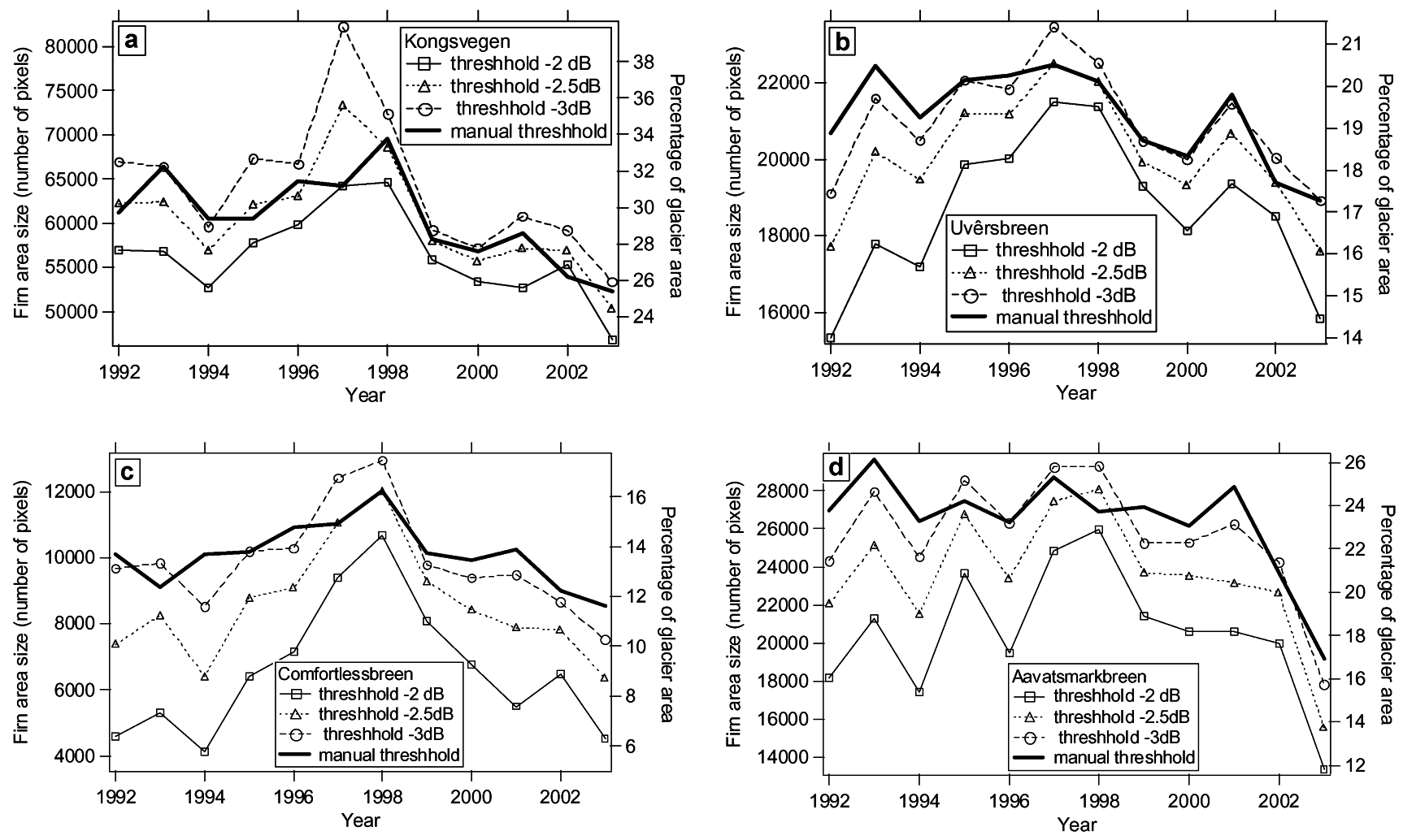

Fig. 6. Firn area size over time as determined from the manual thresholds from Table 2, as well as from applying a constant threshold of -2, -2.5 and $-3 \mathrm{~dB}$. For Kongsvegen ( $a$ ), a constant threshold of $-2.5 \mathrm{~dB}$ gives results very similar to the manual thresholds from Table 2. For Uvêrsbreen (b), Comfortlessbreen (c) and Aavatsmarkbreen (d), a threshold closer to $-3 d B$ gives results similar to the manual threshold values. The area size is given in pixels $(20 \times 20 \mathrm{~m}$ each) as well as percentage of the total classified glacier area.

order to remove isolated pixels and noise (see further below). A retreat of the firn-line position is easily detected on Kongsvegen, most noticeably in recent years (Fig. 5). On the other glaciers, a retreat of the firn-line position is only minor on the thresholded SAR image (not shown). The retreat is better quantified in Figure 6, where the firn area size is plotted against time. The firn area size is fairly constant except for a decrease in recent years. This is in agreement with the glacier mass balance measured on Kongsvegen, whose average is around zero, except for a larger occurrence of negative mass-balance years since 1999 (Table 2). For Kongsvegen, we thus have a case as described in section 4, where a number of negative massbalance years leads to a decrease in firn area extent and a retreat of the firn line.

So far, the thresholds in Table 2 need to be determined manually as described above. For an operational application of this method, however, we would like to automate the threshold determination without any user interaction. A simple, automatic minimum detection on the histogram, however, fails in many cases where the histogram peaks are less well separated, even though the firn-line position is still easy to see visually in the SAR images. An attempt to create a two-dimensional $(x-y)$ version of the segmentation filter discussed earlier also proved unsuccessful. Since the firn line is observed so clearly in each image, it is likely that more sophisticated image classification methods would succeed. This will have to be a topic for future research.

Engeset and others (2002) suggested using a constant threshold of $-2.5 \mathrm{~dB}$ for firn area detection on Svalbard. Considering the variations of the manually detected thresholds in Table 2, this initially seems inaccurate. In Figure 6 we have plotted firn area extent as determined with the manual threshold from Table 2, as well as firn area extent as determined with constant thresholds of $-2,-2.5$ and $-3 \mathrm{~dB}$. For Kongsvegen, the curves correlate surprisingly well with a constant threshold of $-2.5 \mathrm{~dB}$. The areal extent and the firnline position in single years are also quite similar on the image itself (Fig. 7). For the remaining glaciers, a threshold of $-2.5 \mathrm{~dB}$ underestimates the firn area extent compared to the manual threshold. Figure 7 shows the situation for the year 1994, in which a constant threshold of $-2.5 \mathrm{~dB}$ underestimates the firn area for all glaciers (see Fig. 6). Visually, a major underestimation is only seen on Comfortlessbreen (Fig. 7). For Uvêrsbreen, Comfortlessbreen and Aavatsmarkbreen, the firn areas from a manual threshold correlate much better with a constant threshold closer to $-3 \mathrm{~dB}$ (Fig. 6). General trends, however, are seen equally in all curves in Figure 6. We can conclude that a manual threshold determination is preferable, but a constant threshold as suggested by Engeset and others (2002) will also give satisfactory results. The threshold will have to be set somewhat lower, however, than the suggested value of $-2.5 \mathrm{~dB}$.

Besides the four larger glaciers mentioned above, we have also tested this method on the smaller glaciers on Brøggerhalvøya. The method should in principle work on these glaciers as well, but is very much limited by the fact that the firn area extent is very small and in close proximity to steep mountainsides. On Brøggerhalvøya, all firn areas were hidden in the shadow or in the layover from the steep mountains surrounding these glaciers, making firn area observation impossible.

As mentioned above, a filter needs to be applied after thresholding in order to remove isolated pixels and noise 

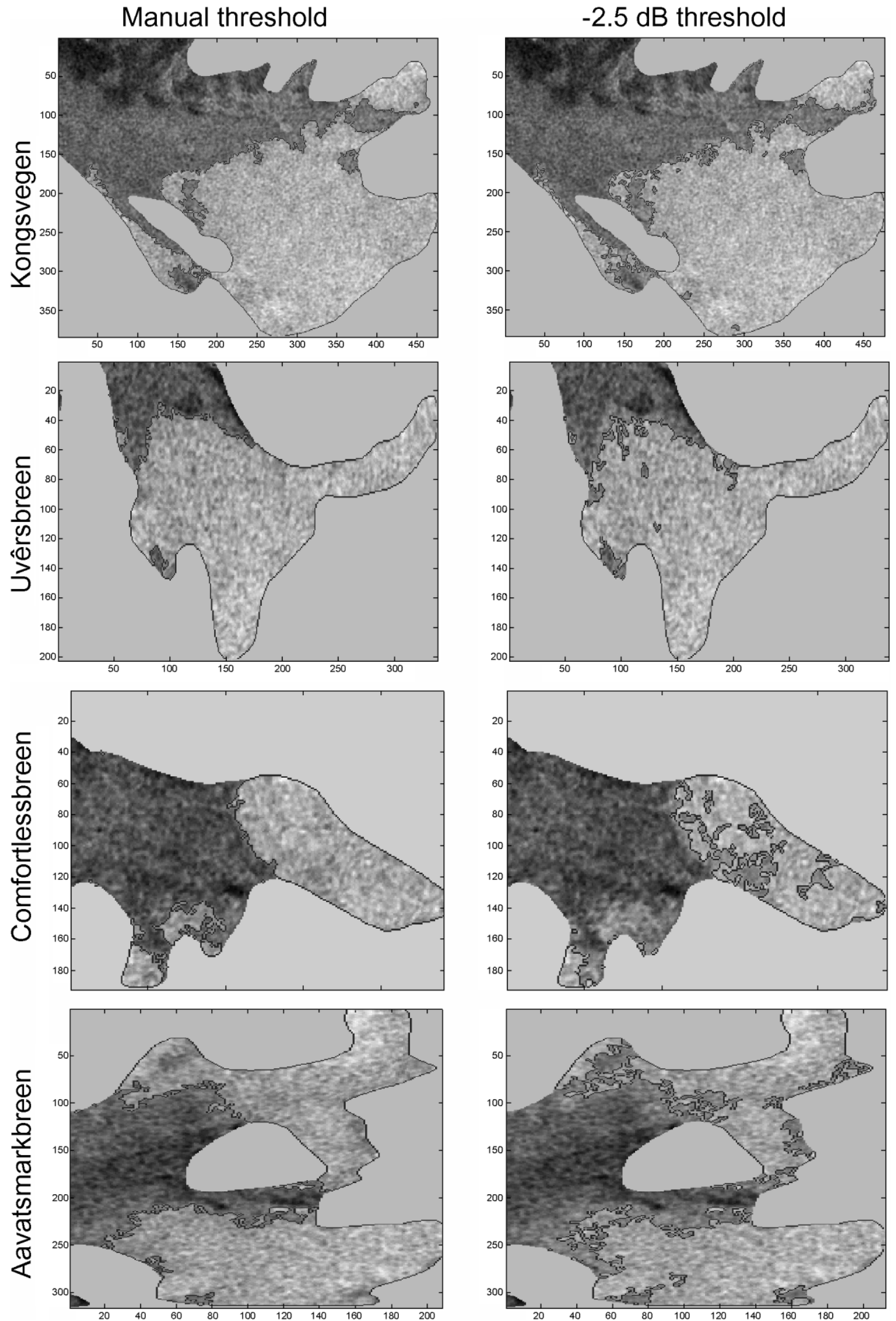

Fig. 7. A close-up of the firn areas of the various glaciers comparing the results in 1994 from applying the manual thresholds in Table 2 against the results from applying a constant threshold of $-2.5 \mathrm{~dB}$. For Kongsvegen, the differences are minor. A large underestimation of the firn area from the $-2.5 \mathrm{~dB}$ threshold is seen on Comfortlessbreen. The locations of the glaciers are marked as rectangles in Figure 2. 

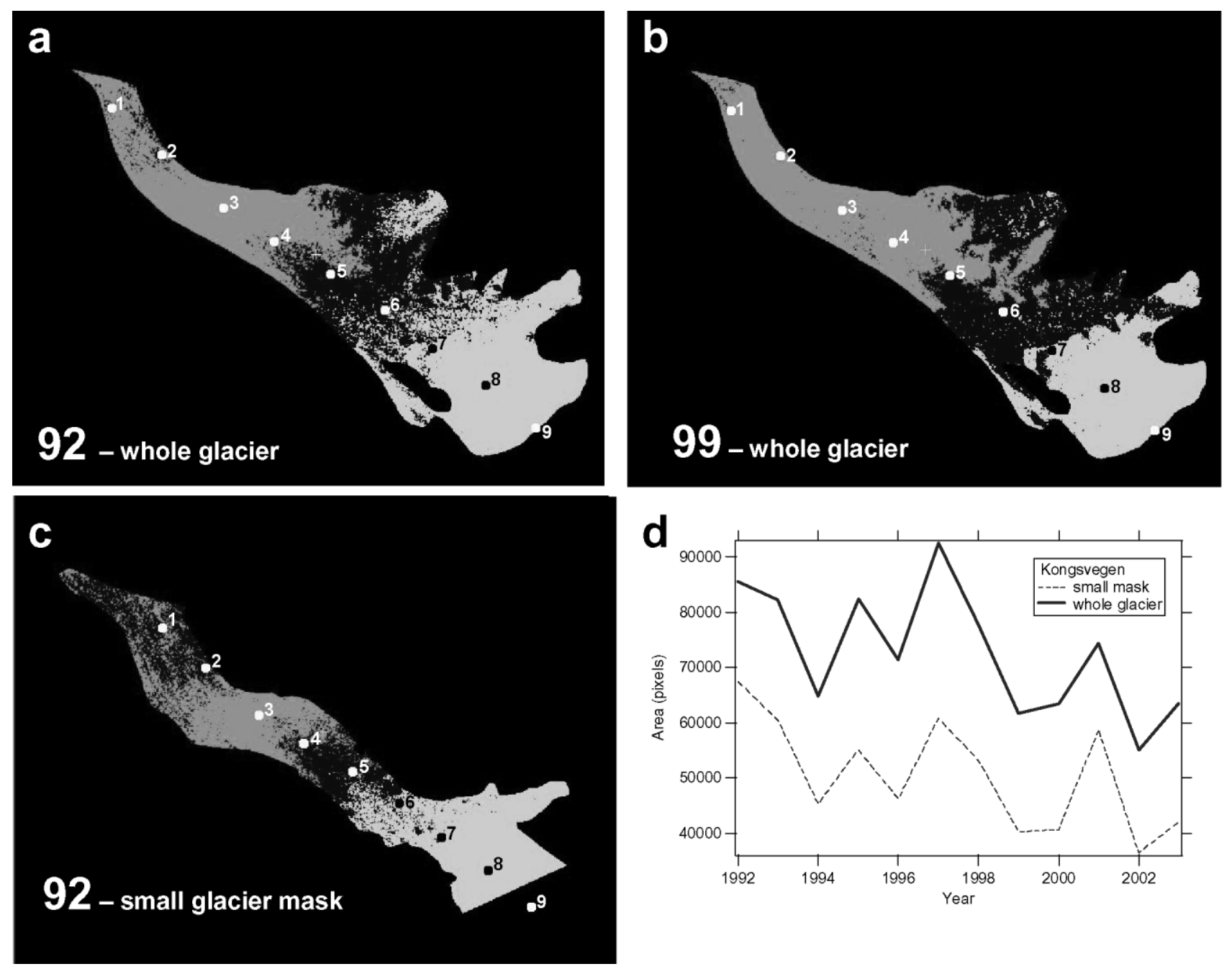

Fig. 8. Results for 1992 and 1999 from a k-means classification of the Kongsvegen glacier surface into three classes for the total glacier surface. The brightest area on the highest part of the glacier is the class whose area change over time correlates with glacier mass balance. Classifying a smaller surface area of Kongsvegen (c) gives a larger area size for this class on the glacier's upper part, but relative area changes remain the same (d). See Figures 1 and 2 for location and scale (comparing the marked stake positions).

within the firn area. Engeset and others (2002) used a speckle filter for this purpose. Filters of this type typically use a moving window of $3 \times 3$ or $5 \times 5$ pixels. Each centre pixel is then replaced with the mean, median or some other measure of the surrounding $3 \times 3$ or $5 \times 5$ pixel window. The disadvantage of these filters is their tendency to move boundaries and smooth sharp edges. We also encountered this problem when using speckle filtering as suggested in Engeset and others (2002). For the values presented in this paper, we therefore applied a regional maxima and minima filter instead, as described in Soille (1999: 170-171), and implemented in Matlab ("imhmax" and "imhmin"). This more advanced filter detects regional extrema within a homogeneous area and removes them. In contrast to a speckle filter, this filter does not use a moving window and its application leaves boundaries virtually unchanged.

Like the firn area, the superimposed-ice and glacier areas can be separated by selecting the corresponding threshold (e.g. $-9 \mathrm{~dB}$ in Fig. 4 b). The extent of the superimposed-ice area, however, seems to be stable. This appears reasonable since superimposed-ice extent is largely determined by topography, which controls the free flow of meltwater and thus is less dependent on any real glacier changes, although long-term trends should also show an effect. On Kongsvegen, no conclusive changes in the superimposed- ice area are seen, so we only consider firn area changes in this paper.

In summary, our method for firn area monitoring consists of thresholding the SAR image, preferably with a manually determined threshold, or with a constant threshold of -2.5 to $-3 \mathrm{~dB}$, followed by a regional extrema filter in order to remove noise and isolated pixels.

\section{MASS-BALANGE MONITORING VIA $k$-MEANS GLASSIFICATION}

Since glacier ice, superimposed ice and firn are so clearly observed visually on the SAR images, we had assumed that a simple $k$-means classification of the glacier surface into three classes would faithfully display these three surface types.

The $k$-means algorithm takes $k$ random points and assigns each of the remaining points to the closest of the random points. This results in $k$ clusters of points. The mean of these $k$ clusters is determined and the whole process started again: Each point is assigned to the closest of the cluster means. This again results in $k$ new clusters, whose new mean is determined. The process is repeated and, if it converges, 

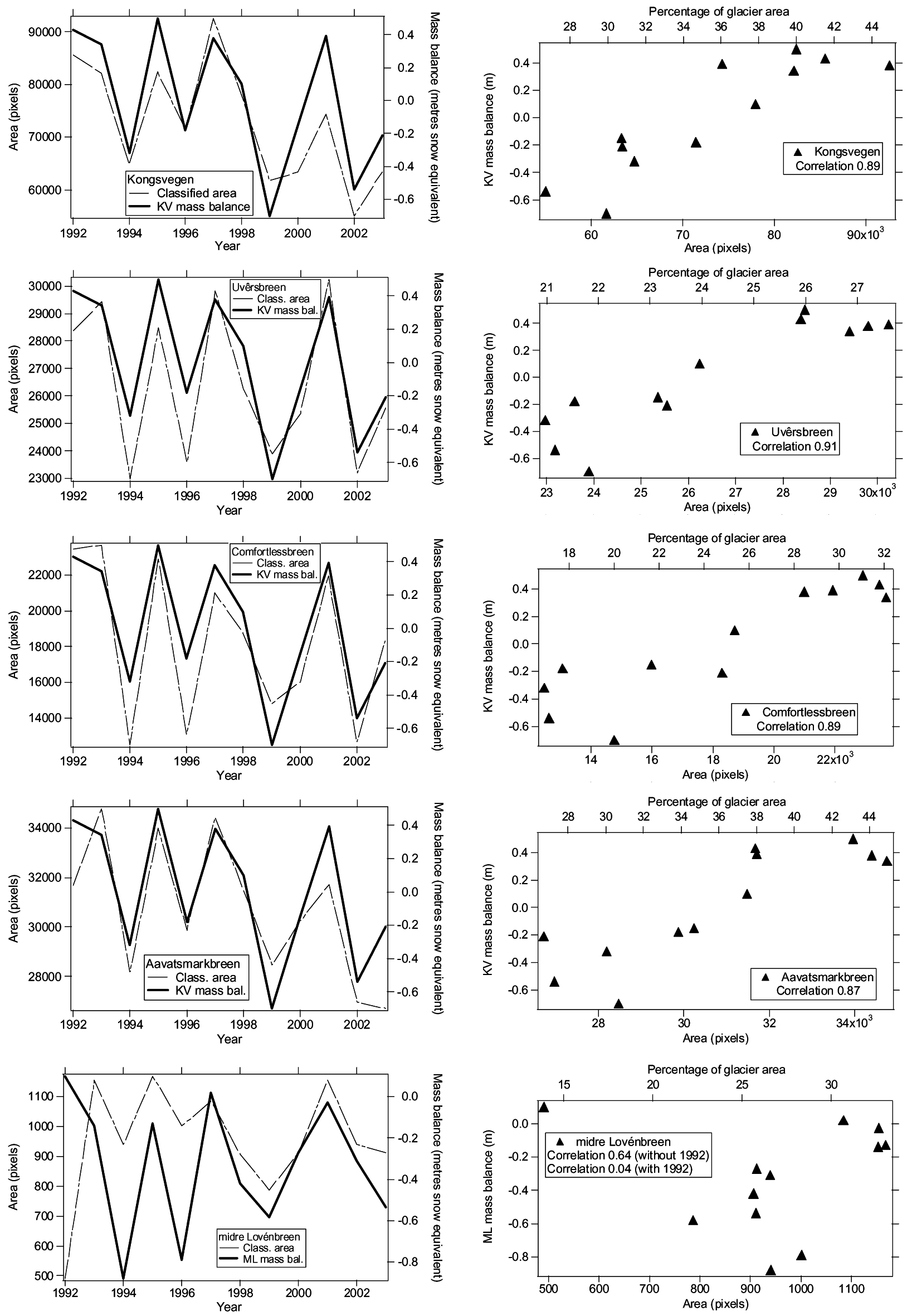

Fig. 9. The area size of the class on the upper part of the glacier, as determined with a k-means classification, correlates remarkably well with the mass balance for all glaciers in the study area. The correlation is calculated using Kongsvegen (KV) mass balance, except for midre Lovénbreen (ML) where this glacier's own mass balance is available. The area size is given in pixels $(20 \times 20 \mathrm{~m}$ each) and, on the graphs to the right, also as percentage of the total classified glacier area. Note that the years indicate the spring in which the SAR images were taken. These show the mass-balance situation from the end of the previous summer (e.g. the 1992 image shows the 1990/91 mass-balance year). 


\section{Negative mass balance}

Snow lies very high, little influence

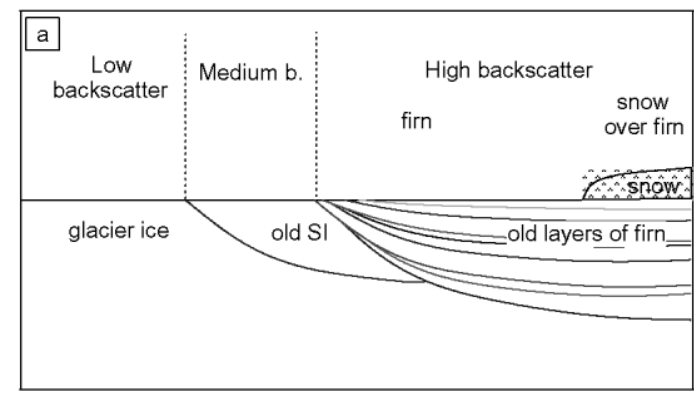

$\rightarrow \quad$ histogram as if no snow were present

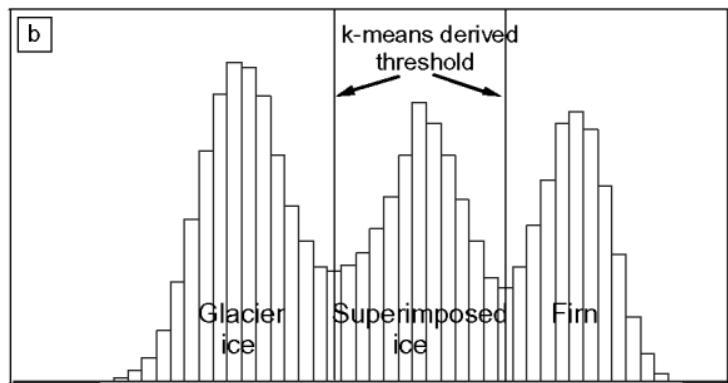

\section{Positive mass balance}

Snow covers firn and parts of superimposed ice (SI)

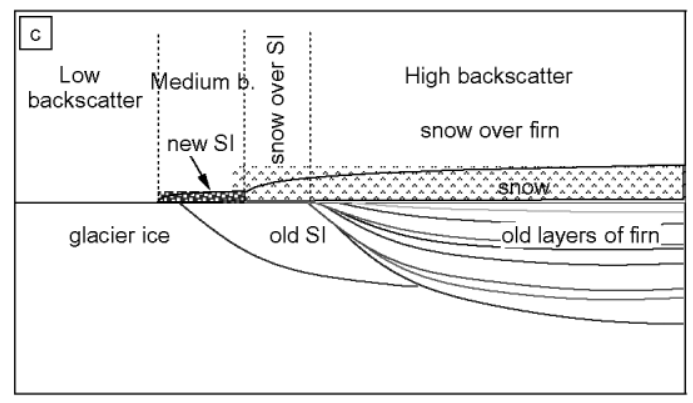

Two effects on k-means:

1) Previous firn peak has more values since it now contains snow over SI in addition to snow over firn.

2) Shape change due to this may cause threshold to move slightly to the left.

\section{$\Rightarrow$ Number of values in righthand peak}

increases with positive mass balance.

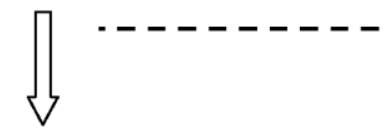

snow over SI adds influence

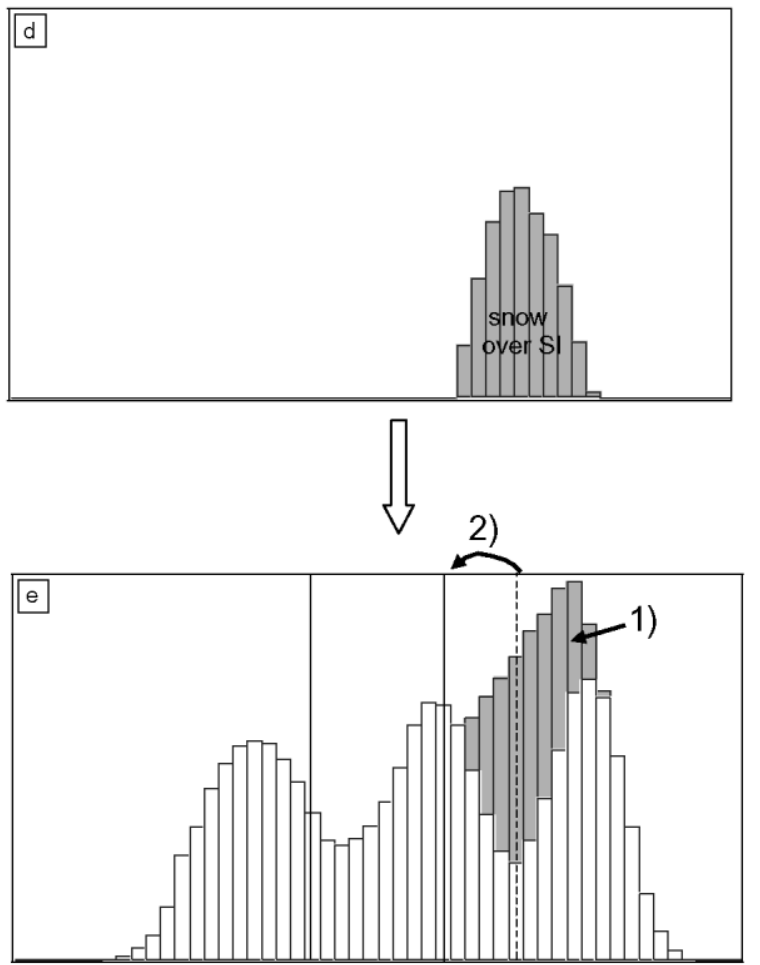

Fig. 10. For a year with very negative mass balance, snow from the accumulation area will have little influence, since snow and firn have comparable backscatter (a). Thus, the histogram of the glacier surface shows the underlying three surface types as three distinct peaks as if no snow were present ( $b$ ). For a year with positive mass balance, snow from the accumulation area extends much lower ( $c$ ), and snow over superimposed ice adds an effect to the underlying surface types as a fourth signature ( $d$ ). This effect is too small to be seen visually on the SAR image (Fig. 1), but is large enough to influence the k-means classification. Both cases (b) and (e) can be seen in the actual histograms in Figure 11.

finally gives $k$ clusters. We have applied the $k$-means algorithm on the glacier surface with three clusters to be found.

In some years, especially where the histogram shows a clear separation of the three surfaces, the $k$-means classification appears to classify the glacier surface quite well into these three surface types (cf. Fig. $8 \mathrm{~b}$ and histogram in Fig. $4 \mathrm{~b})$. In many years, however, the class expected to correspond to the firn area extends considerably below the firnline position (Fig. 8a). Figure 9 shows the areal extent of this class vs time. Surprisingly, the variation of this class correlates not at all with the firn area extent over time, but instead correlates amazingly well with the glacier mass balance of Kongsvegen. The correlation coefficient between the Kongsvegen mass balance and the change in area of this class is around 0.89 for the various glaciers (Fig. 9). A $t$ test tells us that for 12 samples all correlations higher than 0.58 are significant at the $5 \%$ significance level, while all correlations higher than 0.71 are significant at the $1 \%$ significance level. We can therefore say that mass balance and area size are correlated at the $99 \%$ confidence level.

Similar results can be found for the smaller glaciers on Brøggerhalvøya. Due to the much smaller size of the glacier and the classified areas, however, noise and ambiguous areas lead to larger errors than on the larger glaciers. The glacier area to be classified must be chosen more carefully in order to avoid erroneous areas, otherwise a correlation 

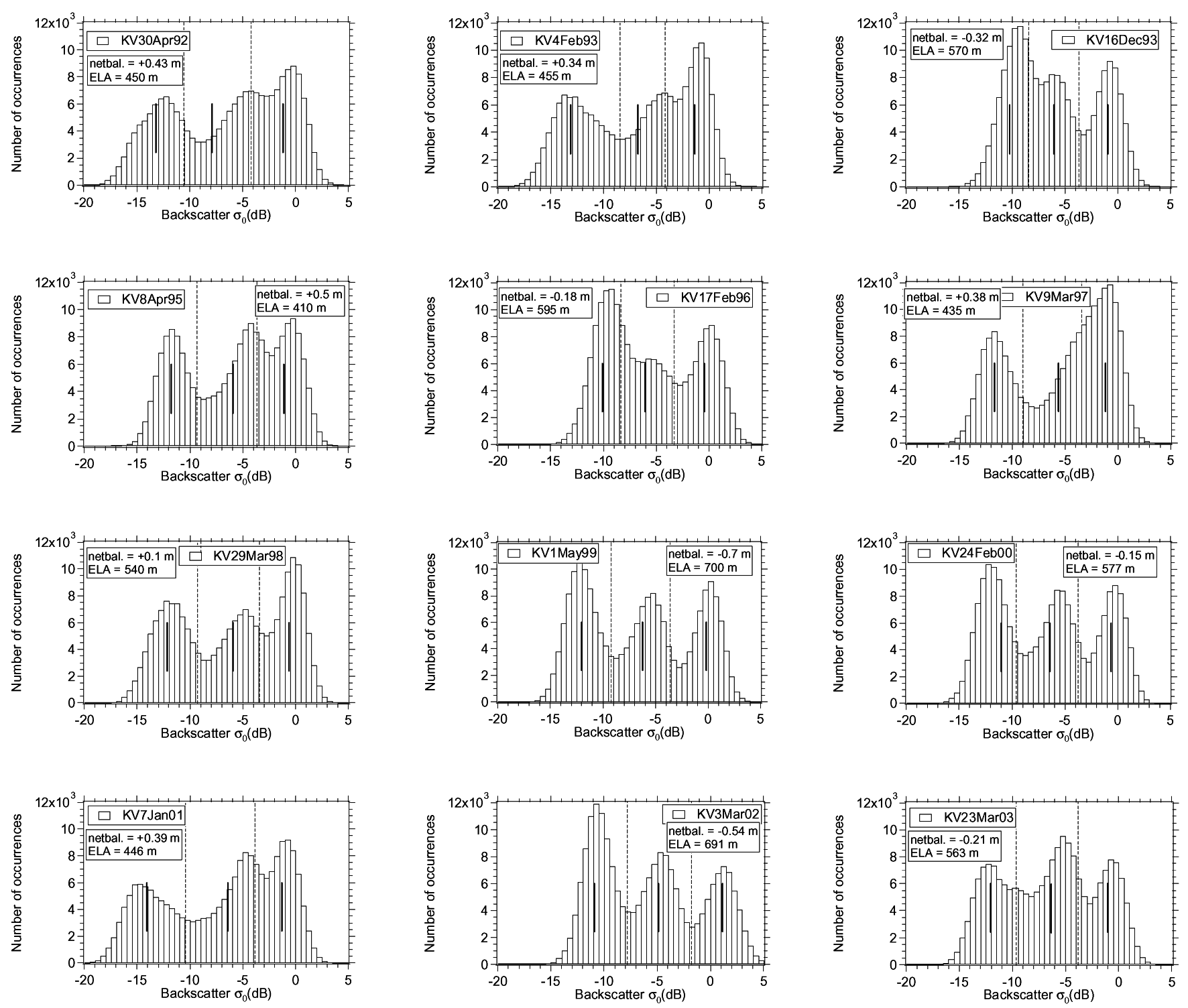

Fig. 11. Histograms from Kongsvegen, 1992-2003. The dotted lines indicate the threshold between the classes as determined by the k-means classification. The shorter, solid lines indicate the mean for each class. The glacier mass balance ("netbal.") and the ELA are given for each graph. In years when the ELA is higher than the firn line ( $\sim 560 \mathrm{~m}$ a.s.l.), the histograms compare well to Figure 10b. In years when the ELA is lower than the firn line, the histograms compare well to Figure 10e.

may be very low or absent. Because of this and the small number of observations, correlation on small glaciers is very sensitive to misclassifications in single years. This is seen on midre Lovénbreen, where the correlation between mass balance and the $k$-means derived area is only 0.04 , but increases to a statistically significant value of 0.64 if the year 1992 is omitted in the calculation (Fig. 9). Austre Lovénbreen has a significant correlation of 0.73 , while Austre Brøggerbreen has a value of 0.7. Correlation values for midre Lovénbreen and Austre Brøggerbreen were calculated with each glacier's own mass balance. Using the Kongsvegen mass balance instead gives a higher correlation for midre Lovénbreen (0.89) but a lower correlation for Austre Brøggerbreen (0.54). These deviations are within the discussed uncertainty due to the small glacier size and the small number of observations.

We have thus found a method for observing mass balance from SAR images by observing the areal extent of the class located highest on the glacier after a $k$-means classification into three classes. The glacier mass balance $(y)$ is related linearly to the $k$-means class (area size $x$ ) located highest on the glacier via $y=a x+b$. The value of $b$ is only known for Kongsvegen. For the other glaciers, the scaling of the curve, factor $b$, is unknown since no mass-balance measurements are available to calibrate the curve to an absolute value. Relative changes, however, can be observed. The fact that $k$-means derived area changes on all the examined glaciers are well correlated with the Kongsvegen mass balance shows that the mass balance of Kongsvegen is representative for its neighbouring glaciers. This correlation would vanish for a glacier with a distinctly different mass balance.

We examined whether a constant threshold would give the same results as the $k$-means classification. For Kongsvegen, areas derived from applying a constant threshold of $4 \mathrm{~dB}$ are highly correlated with the $k$-means area, with a correlation coefficient of 0.9 . The correlation between mass balance and areas obtained using a constant threshold is lower than that between mass balance and the $k$-means derived areas (0.73 vs 0.89 ), although it is still significant. For the other glaciers, however, the correlation coefficients are much lower, just below the significant correlation of 0.71 . Using a constant threshold does not therefore reproduce the results from the $k$-means algorithm.

Figure 8 shows that the method using $k$-means is quite 
robust regarding the glacier area chosen to be classified. The area to be classified needs to include the three surface types (glacier ice, superimposed ice and firn) but must exclude, for example, crevassed areas, which would alter the typical backscatter of these three surface types. Initially, we had only studied the main stream of Kongsvegen (Fig. 8c). Later, we used the exact area of Kongsvegen for our classification, including all tributaries (Fig. 8a). For this larger glacier area, the classified area was much smaller. Relative area changes, however, are exactly the same. Only the absolute area values are different, the area change just being offset (Fig. 8d). Different glacier masks cause a different value distribution, to which the $k$-means algorithm has to adjust. Sometimes, as in Figure 8, a small variation in the threshold value can cause a quite different area extent, indicating a small backscatter increase over a large distance along the centre line. Figure 8, however, shows an extreme example; in other cases, which we examined, this offset in area size was much smaller than that seen in Figure 8d.

The correlation between the areal extent and mass balance is so good that we can assume that the $k$-means classification shows us something very real. The nature of the classified areas is, however, not immediately obvious. It is not visually detectable in the images, nor does the threshold determined by the $k$-means algorithm select an obvious location on the histogram, as seen in Figure 4 where the dotted lines indicate the $k$-means threshholds. On the histogram in Figure $4 \mathrm{~b}$, for example, the $k$-means algorithm chooses all pixels higher than $-3.6 \mathrm{~dB}$ for the area following mass balance, while the minimum in the histogram is located at $-2.6 \mathrm{~dB}$. In the histogram in Figure $4 \mathrm{e}$, the $k$ means algorithm chooses $-4.8 \mathrm{~dB}$ as threshold, again not close to any significant feature in the histogram. The most likely explanation is that the $k$-means derived area is related to the snowline and the accumulation area (Fig. 3), since this area shows annual variations with mass balance. In discussing Figure 3 in König and others (2002), we had assumed that the accumulation area has very little effect on the SAR signal. This was supported by the fact that the SAR images only show the three underlying surface types (glacier ice, superimposed ice and firn), not the accumulation area (Fig. 1). The results of this study indicate that the effect of snow from the accumulation area on the SAR signal is in any case large enough to influence the $k$-means classification. This is illustrated in Figure 10, which like Figure 3 shows the end-of-summer situation of a glacier, as seen in the SAR images throughout the winter.

For a year with a negative mass balance, the snowline will be located high on the glacier, and the accumulation area for that year will be rather small (Fig. 10a). Assuming that snow from the accumulation area affects the SAR signal, an image pixel containing snow over firn will look similar to or the same as a pixel containing only firn, because snow and firn have comparable backscatter values. Therefore, the accumulation area will have little or no effect on the SAR signal, and the histogram will look just as if no snow was present at all, only showing the underlying surface types as three distinct peaks. Each peak represents the signature of one surface type, and the $k$-means classification separates these three surface types (Fig. 10b). This case is well illustrated on Kongsvegen (Fig. 11). In years, where the equilibrium-line altitude (ELA), and thus the snowline, is high above the firn-line altitude ( $\sim 560 \mathrm{~m}$ a.s.l.), the three peaks are separated very clearly (e.g. 1999 and 2002).
For a year with positive glacier mass balance, the snow from the accumulation area extends further down-glacier and covers the firn area and parts of the superimposed-ice area (Fig. 10c). Again, a pixel containing snow over firn will look similar to or the same as a pixel containing only firn. A pixel containing snow over superimposed ice, however, will be distinct from a pixel containing only superimposed ice, since snow and superimposed ice have different backscatter values. Snow over superimposed ice will therefore contribute its own fourth signature (Fig. 10d) to the histogram in Figure 10b. This results in a histogram as shown in Figure $10 \mathrm{e}$, where the two peaks, which previously corresponded to superimposed ice and firn, are now less clearly separated due to the additional presence of the snow on top of superimposed ice. Again, this is seen in the histograms of Kongsvegen (Fig. 11). In years when the ELA extends below the firn-line altitude, the same two peaks are less clearly separated (e.g. 1992 and 2001), as shown schematically in Figure 10e. If the snow cover in Figure 10c extends even lower, covering parts of the glacier ice area as well, there may be an additional effect from snow over glacier ice. This is not seen on Kongsvegen, but could be the case for glaciers with a less extensive superimposed-ice area.

For the $k$-means classification, this has two effects for years with positive mass balance. First, the class previously only containing firn pixels (Fig. 10b) has more occurrences since it now contains pixels with snow over superimposed ice as well as pixels with snow over firn (Fig. 10e). At the same time, the other peaks will have fewer occurrences, since some of their pixels are now in the category snow over superimposed ice. This can be observed on Kongsvegen (Fig. 11), where in years with negative mass balance the firn peak has no more, or fewer, occurrences than the other peaks (e.g. 1999 and 2002). In years with positive mass balance, however, the corresponding peak is highest and has most occurrences compared with the other peaks (e.g. 1992 and 2001). Second, the shape change due to the increase in occurrences in this class may cause the threshold to move slightly, increasing the number of occurrences for this class (Fig. 10e). This is again seen in the histograms (Fig. 11). In negative years (e.g. 2002), the threshold tends to be closer to the minimum between the superimposed ice and the firn peak. In positive years (e.g. 1992), the threshold tends to be located to the left of this minimum. Thus, there are two mechanisms through which the $k$-means derived area increases its size with positive mass balance.

We conclude that a $k$-means classification of the glacier surface on Svalbard glaciers into three classes gives an areal extent on the upper part of the glaciers that is highly correlated with their mass balance. The reason for this correlation is the added influence of the snow from the accumulation area on the backscatter histogram, as illustrated in Figure 10.

\section{GONCLUSIONS}

We have presented two methods for monitoring Svalbard glaciers using wintertime SAR images. The first method monitors the firn area extent over time. Changes in firn area extent are free from strong annual variations, and a retreat or advance of the firn line will show trends on longer timescales. The firn area is displayed by thresholding the SAR image, followed by a regional extrema filter to remove noise 
and isolated pixels. The threshold should preferably be chosen by finding the minimum in the histogram separating superimposed ice and firn, but a constant threshold of -2.5 to $-3 \mathrm{~dB}$ gives acceptable results if manual interaction is not possible or wished for. The filter applied after thresholding must not smooth boundaries or even move them; the filter chosen in this study meets these requirements. A retreat of the firn line and a decrease in firn area extent is seen especially on Kongsvegen, corresponding to a number of consecutive years with negative mass balance.

The second method applies a $k$-means classification to three classes on the glacier surface. The glacier area to be classified should include the three surface types (glacier ice, superimposed ice and firn), but must exclude crevassed areas, which would alter the typical backscatter of these three surface types. The area change of one of the resulting $k$-means derived classes, the one on the upper part of the glacier, correlates extremely well with the glacier mass balance of Kongsvegen. The correlation coefficient of 0.89 is statistically significant. The reason for this high correlation is that the snow from the accumulation area affects the SAR signal, as illustrated in Figure 10. This effect is too small to be seen visually on the SAR image, but is large enough to influence the $k$-means classification.

On glaciers where some mass-balance values are available, this method allows prediction of new mass-balance values solely from SAR images. For glaciers where no mass-balance values are available, the area change cannot be calibrated to absolute mass-balance values, but relative changes can be predicted. In addition, it is possible to say whether the measured mass balance of one glacier is representative for its neighbouring glaciers. For the glaciers in this study, we can therefore conclude that the Kongsvegen mass balance is representative for its neighbouring glaciers, since the area change of all these glaciers correlates remarkably well with the mass balance of Kongsvegen. If any of these glaciers had a different annual variation in its $k$-means derived area, we could have concluded instead that the Kongsvegen mass balance was not representative for this particular glacier.

As a next step, we will attempt a more detailed verification of both methods in areas other than the Kongsfjorden area, first applying the methods on the few other glaciers having mass balance in Svalbard and then analyzing regional mass-balance differences by studying various glaciers all over Svalbard. Whether these methods can successfully be applied to areas other than Svalbard also needs to be examined. Most glaciers on Svalbard are large, with a clear zonation of the surface types and hardly any wintertime melting. Similar conditions may be found in Northern Greenland, but in Norway or in the Alps, for example, wintertime melting and much more wintertime snowfall may cause problems. However, the present study suggests that at least in Svalbard and similar areas these methods have a strong potential for being the first reliable tools for opera- tional glacier mass-balance and firn-line monitoring with SAR images.

\section{AGKNOWLEDGEMENTS}

This study has benefited from fruitful discussions with J. O. Hagen, R. Storvold and O. Brandt. This project is funded by the European Commission (contract No. IST-2000-28766) and the Norwegian Polar Institute. The methods presented will be implemented as operational algorithms for glacier monitoring in Svalbard within the EuroClim project (http://euroclim.nr.no).

\section{REFERENGES}

Davis, J. C. 1986. Statistics and data analysis in geology. Second edition. New York, etc., John Wiley and Sons.

Engeset, R.V., J. Kohler, K. Melvold and B. Lundén. 2002. Change detection and monitoring of glacier mass balance and facies using ERS SAR winter images over Svalbard. Int. F. Remote Sensing, 23(10), 2023-2050.

Fahnestock, M., R. Bindschadler, R. Kwok and K. Jezek. 1993. Greenland ice sheet surface properties and ice dynamics from ERS-1 SAR imagery. Science, 262(5139), 1530-1534.

Guindon, B. and M. Adair. 1992. Analytic formulation of spaceborne SAR image geocoding and "value-added" product generation procedure using digital elevation data. Can. 7. Remote Sensing, 18(1), 2-11.

Hagen, J. O. and O. Liestøl. 1990. Long-term glacier mass-balance investigations in Svalbard, 1950-88. Ann. Glaciol., 14, 102-106.

Hagen, J. O., O. Liestøl, E. Roland and T. Jørgensen. 1993. Glacier atlas of Svalbard and Jan Mayen. Nor. Polarinst. Medd. 129.

Hagen, J. O., K. Melvold, T. Eiken, E. Isaksson and B. Lefauconnier. 1999. Mass balance methods on Kongsvegen, Svalbard. Geogr. Ann., 81A(4), 593-601.

König, M., J.-G. Winther, N.T. Knudsen and T. Guneriussen. 2001a. Firnline detection on Austre Okstindbreen, Norway, with airborne multipolarization SAR. 7. Glaciol., 47(157), 251-257.

König, M., J.-G. Winther and E. Isaksson. 2001b. Measuring snow and glacier ice properties from satellite. Rev. Geophys., 39(1), 1-28.

König, M., J. Wadham, J.-G. Winther, J. Kohler and A.-M. Nuttall. 2002. Detection of superimposed ice on the glaciers Kongsvegen and midre Lovénbreen, Svalbard, using SAR satellite imagery. Ann. Glaciol., 34, 335-342.

Laur, H. and 6 others. 1998. Derivation of the backscattering coefficient $\sigma^{\circ}$ in ESA ERS SAR PRI products. Fifth (b) edition. Noordwijk, European Space Agency. (ESA/ERIN Tech. Note 2; ES-TN-RS-PM-HL09.)

Lefauconnier, B., J. O. Hagen, J. B. Ørbæk, K. Melvold and E. Isaksson. 1999. Glacier balance trends in the Kongsfjorden area, western Spitsbergen, Svalbard, in relation to the climate. Polar Res., 18(2), 307-313.

Liestøl, O. 1988. The glaciers in the Kongsfjorden area, Spitsbergen. Nor. Geogr. Tidsskr., 42(4), 231-238.

Melvold, K. and J. O. Hagen. 1998. Evolution of a surge-type glacier in its quiescent phase: Kongsvegen, Spitsbergen, 1964-95. f. Glaciol., 44(147), 394-404.

Partington, K. C. 1998. Discrimination of glacier facies using multi-temporal SAR data. 7. Glaciol., 44(146), 42-53.

Paterson, W. S. B. 1994. The physics of glaciers. Third edition. Oxford, etc., Elsevier.

Smith, L. C., R. R. Forster, B. L. Isacks and D. K. Hall. 1997. Seasonal climatic forcing of alpine glaciers revealed with orbital synthetic aperture radar. 7. Glaciol., 43(145), 480-488.

Soille, P. 1999. Morphological image analysis: principles and application. Heidelberg, Springer-Verlag.

Winther, J.-G. 1993. Landsat TM derived and in situ summer reflectance of glaciers in Svalbard. Polar Res., 12(1), 37-55. 